\title{
Clinical and prognostic significance of serum transforming growth factor-beta1 levels in patients with pancreatic ductal adenocarcinoma
}

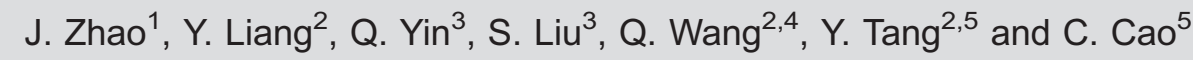 \\ ${ }^{1}$ Department of Clinical Laboratory, People's Hospital of Weifang, Shandong, China \\ ${ }^{2}$ Department of Surgery, People's Hospital of Rizhao, Shandong, China \\ ${ }^{3}$ Department of Oncology, People's Hospital of Rizhao, Shandong, China \\ ${ }^{4}$ Department of Clinical Laboratory, People's Hospital of Zhangqiu, Shandong, China \\ ${ }^{5}$ Department of Medical Laboratory Diagnosis Center, Jinan Central Hospital, Shandong, China
}

\begin{abstract}
Pancreatic ductal adenocarcinoma (PDAC) has a poor 5-year survival rate of $5 \%$. Biomarkers for the early detection of pancreatic cancer are urgently needed. Transforming growth factor-beta1 (TGF- $\beta 1$ ) is elevated in the tissues and plasma of patients with PDAC. However, no studies systemically report prognostic significance of plasma TGF- $\beta 1$ levels in PDAC. In the present study, we assessed the prognostic significance of serum TGF- $\beta$ levels in patients with PDAC. TGF- $\beta$ levels were determined in serum from 146 PDAC patients, and 58 patients with benign pancreatic conditions. Regression models were used to correlate TGF- $\beta$ levels to gender, age, stage, class, and metastasis. Survival analyses were performed using multivariate Cox models. Serum levels of TGF- $\beta 1$ distinguished PDAC from benign pancreatic conditions $(P<0.001)$ and healthy control subjects $(P<0.001)$. Serum levels of TGF- $\beta$ also distinguished tumor stage $(P=0.002)$ and lymph node metastasis $(P=0.001)$. High serum levels of TGF- $\beta 1$ were significantly correlated with reduced patient survival. Multivariate analysis revealed that TGF- $\beta 1$, lymph node metastasis and tumor stage were independent factors for PDAC survival. Our results indicate that serum TGF- $\beta 1$ may be used as a potential prognostic marker for PDAC.
\end{abstract}

Key words: Pancreatic ductal adenocarcinoma; Marker; TGF- $\beta 1$

\section{Introduction}

Pancreatic ductal adenocarcinoma (PDAC) is one of the most fatal cancers, with a 5-year survival of less than $5 \%$ due to its high recurrence rate, despite the multimodality treatments (1). Surgical resection is the only chance of cure, but due to advanced stage at presentation only $20 \%$ of patients have resectable tumors (2). Of these, only $15 \%$ will have early-stage cancers (3). When resection is possible and followed by adjuvant therapy, the 5 -year survival is higher, at $20-30 \%$ (4). It is clear that early detection of smaller tumors is necessary to improve resectability rates and survival.

CA $19-9$ is currently the gold standard serum biomarker for the diagnosis of PDAC. Recent evidence has supported the utility of CA $19-9$ as a prognostic biomarker for PDAC, especially with regards to predicting survival following clinical treatment (5). CEA is likely the second most used biomarker for PDAC. However, neither of the two biomarkers possesses the accuracy desirable for screening asymptomatic populations (6). The past decade has witnessed intensive study and impressive progress in searching for novel biomarkers, but further studies are needed to find more sensitive, specific, and cost-effective biomarkers for diagnosis and prognosis.

Transforming growth factor (TGF)- $\beta$ is involved in physiological processes, such as wound healing, tissue development, and remodeling. TGF- $\beta$ has also been implicated in many pathological conditions, including cancer, and has been shown to regulate a number of events such as angiogenesis, immune suppression, and cell migration $(7,8)$. Clinically, TGF- $\beta 1$ is often elevated in the plasma of patients with esophageal cancer (9), gastric cancer (10), osteosarcoma (11), melanoma (12), and increased serum TGF- $\beta 1$ levels is related with poor prognosis $(13,14)$.

Multiple experimental studies have shown correlations between TGF- $\beta 1$ expression and increased tumorigenicity and increased invasion in pancreatic cancer cells (15). In pancreatic cancer, expression of TGF- $\beta 1$ in the primary tumor can predict survival of patients undergoing surgical 
resection (16). However, its clinicopathological and prognostic significances in serum of patients with PDAC remain unknown.

In the present study, we evaluated the levels of TGF$\beta 1$ in the blood of PDAC patients and its clinical and/or prognostic significance.

\section{Material and Methods}

The People's Hospital of Weifang approved the retrospective use of the data for the study. Data were acquired retrospectively from electronic medical records.

\section{Patients}

Pretreatment serum samples were obtained from 146 patients with histologically or cytologically confirmed PDAC, from January 2006 to December 2010. Serum samples from 58 patients with chronic pancreatitis, benign pancreatic cysts, or other benign pancreatic neoplasms were also analyzed. The variables evaluated included age, gender, tumor size, differentiation status, lymph node involvement and TNM stage. None of the patients with benign pancreatic diseases or the healthy controls (selected from the Center of Physical Examination of People's Hospital of Weifang and Central Hospital of Jinan) had a history of malignancies. Serum from 204 subjects was analyzed in this study (Table 1).

\section{Blood acquisition and serum preparation}

A total of 5-mL venous blood was collected in a sterile $15 \mathrm{~mL}$ plastic Falcon tube, left to clot and then centrifuged at $11,000 \mathrm{~g}$ for $15 \mathrm{~min}$. Serum samples were stored at $-80^{\circ} \mathrm{C}$ until required for the assay.

\section{Detection of TGF- $\beta 1$ expression in serum}

Quantitative enzyme-linked immunosorbent assay (ELISA) kits were used to assess the levels of human TGF- $\beta 1$ according to the manufacturer's instructions. A total of $200 \mu \mathrm{L}$ of prediluted sera was added to microtiter wells precoated with anti-human TGF- $\beta 1$ polyclonal antibodies followed by a biotin-conjugated mouse antiTGF- $\beta 1$ antibodies and streptavidin-horseradish peroxidase. Color was developed using a tetramethyl benzidinehydrogen dioxide mixture and terminated with sulfuric acid. The absorbance of each well was determined using a spectrophotometer.

\section{Statistical analysis}

Data are reported as means \pm SD. The associations between TGF- $\beta 1$ level and clinicopathological variables were examined using the $\chi^{2}$ test. The association with survival was analyzed using Kaplan-Meier analysis and curves were compared using the log-rank test and Cox regression analysis to adjust for other prognostic indicators. The receiver operating characteristic (ROC) curve was determined and the area under the curve (AUC) was calculated as a comparative measure of diagnostic accuracy. Multivariate Cox regression analysis was used to analyze the relationship between independent and dependent variables. All statistical analyses were performed with the IBM SPSS Statistical software (SPSS Statistics 17.0, USA). Statistical significance was defined as $\mathrm{P}<0.05$.

\section{Results}

\section{TGF- $\beta 1$ in the sera of patients and controls}

Serum TGF- $\beta 1$ levels were $57.6 \pm 23.2 \mathrm{ng} / \mathrm{mL}$ (mean \pm SD) in healthy control subjects, $64.5 \pm 27.4 \mathrm{ng} / \mathrm{mL}$ in benign pancreatic conditions, and $237.6 \pm 45.3 \mathrm{ng} / \mathrm{mL}$ in PDAC patients. There was a statistically significant difference between TGF- $\beta 1$ serum levels in patients with PDAC and control groups $(P<0.001)$, but levels were not elevated in patients with benign pancreatic conditions compared to healthy control subjects $(P=0.437)$.

\section{TGF- $\beta 1$ levels and association with clinicopathological characteristics in PDAC}

We used the $57.6 \mathrm{ng} / \mathrm{mL}$ TGF- $\beta 1$ level of the healthy controls as the cut-off value. Values $>57.6 \mathrm{ng} / \mathrm{mL}$ were defined as high, and $\leqslant 57.6 \mathrm{ng} / \mathrm{mL}$ as low. In PDAC patients, $72.6 \%(106 / 146)$ had high TGF- $\beta 1$ levels, and $27.4 \%(40 / 146)$ had low levels. Serum TGF- $\beta 1$ levels were significantly related with tumor stage $(P=0.001)$ and lymph node metastasis $(P=0.001)$. There was no significant correlation between TGF- $\beta 1$ and other factors, such as age, gender, histological differentiation, and distant metastasis.

Table 1. Prognostic factors in multivariate analysis.

\begin{tabular}{lccc}
\hline Variable & Hazard ratio & $95 \% \mathrm{Cl}$ & $\mathrm{P}$ \\
\hline Stage I + II vs stage III + IV & 1.158 & $1.127-2.132$ & 0.012 \\
High TGF- $\beta 1$ level vs low TGF- $\beta 1$ level & 1.213 & $1.204-3.876$ & 0.001 \\
Lymph node metastasis vs non-lymph node metastasis & 1.214 & $1.174-2.930$ & 0.093 \\
Distant metastasis vs no distant metastasis & 1.564 & $1.328-2.635$ & 0.087 \\
High + moderate differentiation vs poor differentiation & 1.132 & $0.678-1.873$ & 0.624 \\
\hline
\end{tabular}

TGF- $\beta 1$ : Transforming growth factor beta1. 

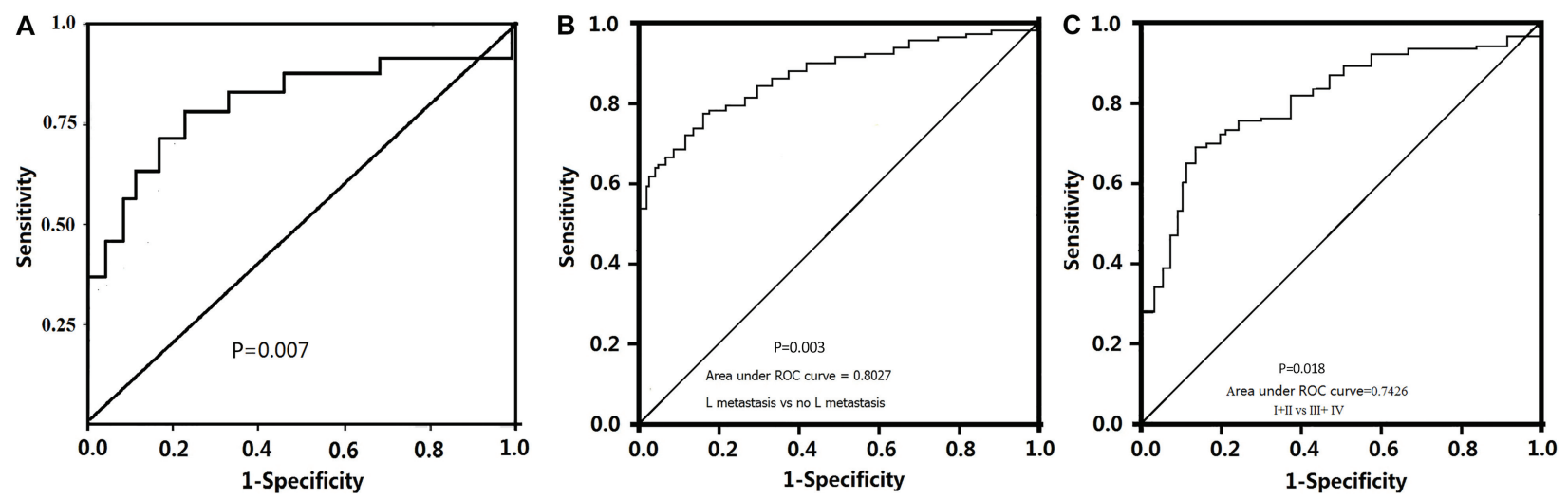

Figure 1. Receiver operating characteristic curve analysis of serum TGF- $\beta 1$ in pancreatic ductal adenocarcinoma patients vs benign pancreas disease $(A)$, for lymph node metastasis vs non-lymph node metastasis $(B)$, and for stage I+II vs stage III + IV (C).
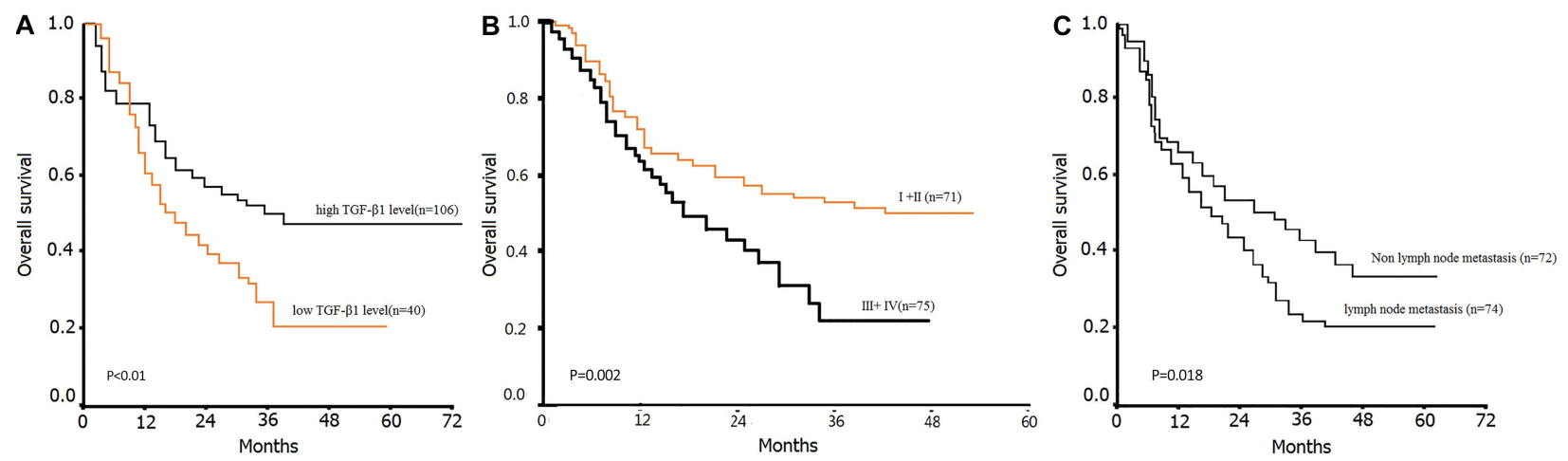

Figure 2. Kaplan Meier survival curve for low and high TGF- $\beta 1$ levels in plasma of pancreatic ductal adenocarcinoma patients $(A)$, for patients with stage I and II or stage III and IV $(B)$, and for pancreatic cancer patients with lymph node metastasis and non-lymph node metastasis $(C)$.

\section{Sensitivity and specificity of TGF $\beta 1$ levels in the diagnosis of PDAC}

ROC curves were generated for serum TGF $\beta 1$ to evaluate its ability to distinguish PDTC from benign pancreas disease, lymph node metastasis from nonlymph node metastasis and stages I and II from stages III and IV. Our results suggest that serum TGF- $\beta 1$ is able to distinguish PDTC from benign pancreas disease with an AUC of 0.794 , specificity of $76.4 \%$ and sensitivity of $83 \%(P=0.007$, Figure $1 A)$. Serum TGF- $\beta 1$ is able to distinguish lymph node metastasis from non-lymph node metastasis with an AUC of 0.8027 , specificity of $80.4 \%$ and sensitivity of $75.6 \%$ ( $P=0.003$, Figure $1 \mathrm{~B})$. In addition, serum TGF- $\beta 1$ distinguished stages I and II from stage III and IV with a AUC of 0.7426 , specificities of $68 \%$ and sensitivity of $72 \%(P=0.0018$, Figure $1 C)$.

\section{Influence of TGF- $\beta 1$ level on overall survival in PDAC}

Median survival from the time of PDAC operation for all patients was 18 months (range of $0.6-26$ months), with a 5-year overall survival of $18.7 \%$. By univariate analysis, the 5 -year median overall survival was $21.7 \%$ in low TGF$\beta 1$ level groups, which was significantly higher than the high TGF- $\beta 1$ level groups (15.3\%; $P<0.01$, Figure $2 A)$.

Cox regression multivariate analysis indicated that only serum TGF- $\beta 1$ level $(P=0.001 ; H R=1.213,95 \% \mathrm{Cl}$ : 1.204-3.876), tumor stage of PDAC ( $P=0.012$; $H R=$ $1.158,95 \% \mathrm{Cl}: 1.127-2.132)$ and lymph node metastasis $(P=0.018 ; \mathrm{HR}=1.214,95 \% \mathrm{Cl}: 1.374-2.93)$ were independent prognostic factors for patients with PDAC (Table 1). Kaplan-Meier survival curves for stage and lymph node metastasis of PDAC are shown in Figure $2 \mathrm{~B}$ and $\mathrm{C}$ ).

\section{Discussion}

TGF- $\beta 1$ is a pleiotropic cytokine that, depending on the cell niche, can display either anti-inflammatory or proinflammatory effects (17). A recent study has found that TGF- $\beta 1$ could shape the metastatic niche and favor the maintenance of an immunosuppressive phenotype in 
mesenchymal cells (18-20). TGF- $\beta$ has a dual role in tumor development including tumor suppression through inhibition of proliferation and induction of apoptosis in multiple cell types, or promotion of tumor cell invasiveness and metastasis through modulation of the immune system as well as of the tumor microenvironment (21). Many studies have found that TGF- $\beta 1$ is activated and released into the blood under ischemia and hypoxia stress, and it is markedly induced and rapidly activated in the infarcted myocardium. Bioactive TGF- $\beta 1$ is released in the cardiac extracellular fluids $3-5 \mathrm{~h}$ following reperfused infarction (22). Tissue and serum TGF- $\beta 1$ were also significantly increased in patients with cancers, indicating its predictive and prognostic roles in patients with this disease.

In our study, serum levels of TGF- $\beta 1$ were found to be significantly higher in PDAC patients than in normal controls or patients with benign pancreas disease. Furthermore, the serum TGF- $\beta 1$ level increased with increased tumor stage, lymph node metastasis and distant metastasis. These findings are supported by Lin et al. $(10,11)$, who stated that TGF- $\beta 1$ levels reflected tumor stage and metastasis.

\section{References}

1. Gong Z, Holly EA, Bracci PM. Survival in population-based pancreatic cancer patients: San Francisco Bay area, 19951999. Am J Epidemiol 2011; 174: 1373-1381, doi: 10.1093/ aje/kwr267.

2. Hidalgo M. Pancreatic cancer. N Engl J Med 2010; 362: 1605-1617, doi: 10.1056/NEJMra0901557.

3. Tascilar M, Skinner HG, Rosty C, Sohn T, Wilentz RE, Offerhaus GJ, et al. The SMAD4 protein and prognosis of pancreatic ductal adenocarcinoma. Clin Cancer Res 2001; 7: 4115-4121.

4. Sultana A, Cox T, Ghaneh P, Neoptolemos JP. Adjuvant therapy for pancreatic cancer. Recent Results Cancer Res 2012; 196: 65-88, doi: 10.1007/978-3-64231629-6.

5. Hernandez JM, Cowgill SM, Al-Saadi S, Collins A, Ross SB, Cooper J, et al. CA 19-9 velocity predicts disease-free survival and overall survival after pancreatectomy of curative intent. J Gastrointest Surg 2009; 13: 349-353, doi: 10.1007/ s11605-008-0696-3.

6. Homma T, Tsuchiya R. The study of the mass screening of persons without symptoms and of the screening of outpatients with gastrointestinal complaints or icterus for pancreatic cancer in Japan, using CA19-9 and elastase-1 or ultrasonography. Int J Pancreatol 1991; 9: 119-124, doi: 10.1007/BF02925587.

7. Kim JE, Lee KT, Lee JK, Paik SW, Rhee JC, Choi KW. Clinical usefulness of carbohydrate antigen $19-9$ as a screening test for pancreatic cancer in an asymptomatic population. J Gastroenterol Hepatol 2004; 19: 182-186, doi: 10.1111/j.1440-1746.2004.03219.x.

8. Zhao HW, Li YW, Feng R, Yu JB, Li J, Zhang Y, et al. TGF-beta/Smad2/3 signal pathway involves in U251 cell
Recent investigations of patients with PDAC have shown significantly elevated serum levels of TGF- $\beta 1$, which could be well correlated with the risk of death (23). In this study, data clearly showed that patients with elevated TGF- $\beta 1$ in the serum had a shorter survival. Furthermore, TGF- $\beta 1>57.6 \mathrm{ng} / \mathrm{mL}$ had a sensitivity of $83 \%$ and a specificity of $76.4 \%$ for detecting individuals with PDAC. In addition, multivariate analysis showed that TGF- $\beta 1$ is an independent prognostic factor. We believe that TGF- $\beta 1$ may be considered to be a biomarker for predicting the probability of PDAC in the future. We also found in our study that TGF- $\beta 1$ levels are predictive of metastasis. We found that high baseline TGF- $\beta 1$ levels were the best predictor of PDAC metastasis. TGF- $\beta 1$ levels were significantly higher in patients with metastasis compared to those without it. Furthermore, TGF- $\beta 1$ could also distinguish stage I and II from stage III and IV.

In conclusion, we found that patients with high TGF- $\beta 1$ plasma levels had an increased risk of metastasis and advanced PDAC. In addition, the high levels were associated with short survival and poor prognosis of PDAC. Our results indicate that serum TGF- $\beta$ may be used as a potential prognostic marker for the PDAC.

proliferation and apoptosis. Gene 2015; 562: 76-82, doi: 10.1016/j.gene.2015.02.049

9. Tas F, Yasasever CT, Karabulut S, Tastekin D, Duranyildiz D. Serum transforming growth factor-beta1 levels may have predictive and prognostic roles in patients with gastric cancer. Tumour Biol 2015; 36: 2097-2103, doi: 10.1007/ s13277-014-2817-9.

10. Lin Y, Kikuchi S, Obata Y, Yagyu K. Serum levels of transforming growth factor beta1 are significantly correlated with venous invasion in patients with gastric cancer. J Gastroenterol Hepatol 2006; 21: 432-437, doi: 10.1111/ j.1440-1746.2005.03939.x.

11. Xu S, Yang S, Sun G, Huang W, Zhang Y. Transforming growth factor-beta polymorphisms and serum level in the development of osteosarcoma. DNA Cell Biol 2014; 33: 802-806, doi: 10.1089/dna.2014.2527.

12. Tas F, Karabulut S, Yasasever CT, Duranyildiz D. Serum transforming growth factor-beta 1 (TGF-beta1) levels have diagnostic, predictive, and possible prognostic roles in patients with melanoma. Tumour Biol 2014; 35: 72337237, doi: 10.1007/s13277-014-1984-z.

13. Bartscht $T$, Lehnert $H$, Gieseler F, Ungefroren $H$. The Src family kinase inhibitors PP2 and PP1 effectively block TGF-beta1-induced cell migration and invasion in both established and primary carcinoma cells. Cancer Chemother Pharmacol 2012; 70: 221-230, doi: 10.1007/ s00280-012-1904-0.

14. Sergeant G, van Eijsden R, Roskams T, Van Duppen V, Topal B. Pancreatic cancer circulating tumour cells express a cell motility gene signature that predicts survival after surgery. BMC Cancer 2012; 12: 527, doi: 10.1186/14712407-12-527. 
15. Rosado E, Schwartz Z, Sylvia VL, Dean DD, Boyan BD. Transforming growth factor-beta1 regulation of growth zone chondrocytes is mediated by multiple interacting pathways. Biochim Biophys Acta 2002; 1590: 1-15, doi: 10.1016/ S0167-4889(02)00194-5.

16. Kajdaniuk D, Marek B, Borgiel-Marek H, Kos-Kudla B. Transforming growth factor beta1 (TGFbeta1) in physiology and pathology. Endokrynol Pol 2013; 64: 384-396, doi: 10.5603/EP.2013.0022.

17. Rodriguez TM, Saldias A, Irigo M, Zamora JV, Perone MJ, Dewey RA. Effect of TGF-beta1 stimulation on the secretome of human adipose-derived mesenchymal stromal cells. Stem Cells Transl Med 2015; 4: 894-898, doi: 10.5966/ sctm.2015-0012.

18. Del Pozo Martin Y, Park D, Ramachandran A, Ombrato L, Calvo F, Chakravarty $\mathrm{P}$, et al. Mesenchymal cancer cell-stroma crosstalk promotes niche activation, epithelial reversion, and metastatic colonization. Cell Rep 2015; 13 : 2456-2469, doi: 10.1016/j.celrep.2015.11.025.

19. Petanidis S, Kioseoglou E, Domvri K, Zarogoulidis P, Carthy $\mathrm{JM}$, Anestakis $\mathrm{D}$, et al. In vitro and ex vivo vanadium antitumor activity in (TGF-beta)-induced EMT. Synergistic activity with carboplatin and correlation with tumor metastasis in cancer patients. Int J Biochem Cell Biol 2016; 74: 121-134, doi: 10.1016/j.biocel.2016.02.015.

20. Plaks V, Kong N, Werb Z. The cancer stem cell niche: how essential is the niche in regulating stemness of tumor cells? Cell Stem Cell 2015; 16: 225-238, doi: 10.1016/ j.stem.2015.02.015.

21. Massague J. TGFbeta in Cancer. Cell 2008; 134: 215-230, doi: 10.1016/j.cell.2008.07.001.

22. Birdsall HH, Green DM, Trial J, Youker KA, Burns AR, MacKay CR, et al. Complement C5a, TGF-beta 1, and MCP-1, in sequence, induce migration of monocytes into ischemic canine myocardium within the first one to five hours after reperfusion. Circulation 1997; 95: 684-692, doi: 10.1161/ 01.CIR.95.3.684.

23. Lin $\mathrm{Y}$, Kikuchi S, Tamakoshi A, Obata Y, Yagyu K, Inaba $\mathrm{Y}$, et al. Serum transforming growth factor-beta1 levels and pancreatic cancer risk: a nested case-control study (Japan). Cancer Causes Control 2006; 17: 1077-1082, doi: 10.1007/ s10552-006-0048-0. 